\title{
Effective principles in the foreign language education
}

\author{
Alexander Kabanov ${ }^{1}$, Nelly Savelyeva ${ }^{1, *}$, Natalie Nevraeva ${ }^{1}$, Natalia Vlasova ${ }^{1}$, Tamara \\ Pyrkova $^{1}$, and Elvira Popova ${ }^{2}$ \\ ${ }^{1}$ Ural Federal University, Ekaterinburg, Russia \\ ${ }^{2}$ Ural State Agrarian University, Ekaterinburg, Russia.
}

\begin{abstract}
In modern reality, when economic, trade, scientific and cultural ties are rapidly developing in the world, exchanges are being carried out in the scientific and technical fields, knowledge of a foreign language becomes a priority for specialists of almost all levels. The very concept of a "foreign language" is increasingly being replaced by a "language of communication" in various fields of culture, science and technology. There are many different languages in the world, and even more dialects. But the trends are such that for most people knowledge of one common language is enough. And this language does not have to be native to the interlocutors. A common language is able to unite different peoples and cultures, even absolutely opposite, into one common cause. In addition to strengthening cultural ties, the language brings together experts in science and technology. At the same time, the authors acknowledge, the lack of research in modern pedagogical science devoted to identifying the potential of information and communication technologies in the process of professional foreign language training of future specialists that meet the requirements of the Russian state and society, imposed on modern specialists of different profiles, reflected in national and international documents.
\end{abstract}

\section{Introduction}

The educational process in higher education institutions must be built taking into account current trends and conditions of interaction between economic partners, as well as the requirements and features of the production process. The study of a foreign language while studying at the University should become professionally oriented in order to develop and bring to automatism the skills of speaking and writing a foreign language with a parallel study of the technical aspects of production [1].

The desire of manufacturers to reduce the cost of production has given rise to such a phenomenon in society as optimization. This concept is firmly established in our life and has spread not only in industrial production, but also in all other areas of the national economy, generating along with economic benefits and many negative phenomena.

\footnotetext{
* Corresponding author: nellik1983@mail.ru
} 
For example, in a higher education institution, if the lecturer's workload increases, the quality of training of future specialists may decrease, and the rating of the institution will become lower. If the load is reduced, more lecturers will be required and thus the profitability of the University will decrease that will also not improve economic indicators.

In this situation, new, non-standard approaches to teaching are needed. The use of modern educational information and communication technologies gives the teacher a wide opportunity to convey the educational material simultaneously to different categories of students - with different levels of initial training, with different speed of perception and sometimes with different attitudes to education at the University. This dramatically reduces the number of underachieving students, motivates them to study, makes learning more effective, raises it to the proper level, and, accordingly, increases the rating of the University.

\section{Results and Discussion}

When teaching a foreign language at University, the following principles should be followed:

- availability of all educational material;

- multi-level individual approach;

- various forms of presentation of the acquired educational material by students;

- quality control of learning materials.

Let's look at the listed principles of training in more detail.

Availability of all educational material.

The modern student is far from the idea of spending hours in the library or looking for a rare book. And it's not about laziness. Today, the flow of information from various sources is so high that there is simply no time to process it. Information can be useless. But to understand this, it is necessary to perceive it and extract useful points, i.e. to spend a certain amount of time on it [2].

Optimizing the cost of processing information sources will make the course more effective, and the quality of training, demand for specialists, and as a result, the University's rating will increase accordingly. To do this, you need to provide information in a readymade form, you need to specify all the sources necessary for training in the course and systematize them. Another option is to learn how to use search engines and numerous databases, namely, to formulate correctly a request to search for the desired material in both native and foreign languages. Knowledge of foreign languages in this case increases the ability to use search engines and databases, increases their efficiency in providing the necessary information [3].

Another factor in the availability of educational material is compactness. A bag full of textbooks can't be as useful in learning today as it was a few years ago, nor can countless bookcases and shelves. The modern development of electronics and mobile Internet allows you to fit in your pocket entire libraries that contain and instantly provide the user with all the necessary information. In modern men, everything should fit in the palm of your hand: in a smartphone or tablet, or at least in a laptop. In turn, the speed of devices and their memory are the main parameters for purchasing them.

Multi-level individual approach. Students from different regions, large and small cities, and even countries are concentrated at universities. The level of initial training varies. In addition, students with different temperaments and speed of learning material after school and technical school moved to a higher level of training, joined a new team. They need to adapt to other requirements, a more rigorous approach to training, heavy loads, etc.

In addition, students who live in a hostel must get used to other living conditions. Often, young people living with their parents do not do some work at home. Adaptation takes 
place in different ways for everyone. A long adaptation period can lead to low academic performance, so these factors must be taken into account at the basic level of learning a foreign language at the University.

In the first days of training, when meeting students, it is necessary to identify the capabilities of each of them, i.e. initial training in the subject. In principle, this is not difficult. The lecturer sees the temperament of each student, who communicates with whom, and how students feel about the implementation of the curriculum. The level of preUniversity training can be determined by conducting entrance testing, which will create extra stress and so "impressed with the new realities" of the student or after two or three sessions it will become clear.

By the middle of the first semester, you can already assess the level of diligence of students. At this stage, students still apply to study at the University based on school experience. Some believe that they will "hold out" and there is no need to make any effort; others are guided by a high assessment, rather than a professional perspective.

Taking into account this difference in initial training and attitude to studying at the University, it is necessary to organize work both in the classroom and independently outside of the educational institution. In particular:

- Allow free movement during classroom sessions. In general, university students are disciplined, and such "freedom" does not lead to undesirable consequences. On the contrary, it can be observed that some students prefer to work in small groups or pairs, while others prefer to work alone. This arrangement can be used more effectively in the learning process. Based on world experience, strict rules of behavior in the classroom do not improve academic performance, and freedom of action within the course helps to create a favorable atmosphere in the classroom.

- *In subgroups, identify "strong" and "weak" students and offer them different options for interaction, for example, if a " weak "student achieves certain success, then the "strong" one gets positive marks for it, since he has already shown his knowledge by passing it to his friend. As for students who prefer to work alone, observations have shown that there are not so many of them, and more attention can be paid to them with this approach. In addition, the number of students in higher education is reduced.

- Thanks to the electronic course and modern information and communication technologies, a comfortable learning environment is created for students. This also applies to the rate of completion of the course. It is not possible to set the same rate of learning. It depends on the individual qualities of the person.

Basically, debts arise in cases when students do not have time to complete one task, they are offered a second, third..., the student loses his reference point in time and as a result finds himself at the end of the semester with debts. With the traditional approach to the learning process, it is the "delivery of debts" that compensates for the difference in the rate of perception of information. Skipping classes for any "respectful" or "disrespectful" reasons also provoke delays, as they affect the pace of learning.

Given that the foreign language course at the University is based on initial training, there is no need to adhere to a strict sequence, as in the primary study of the material. The main task is to apply and expand the existing knowledge in a professional direction. This gives you a wide choice of the sequence of stages of tasks, and, accordingly, the pace of study. The student chooses what he / she works with the text today, then participates in the creation of the film, then writes annotations, etc. Thus, each student in the group has his / her own path to the final result. The lecturer gives" point-by-point» consultations, while not spending time explaining all the training material (the one that students already know). The saved time resources are spent on solving more difficult tasks, working with debts (which are inevitably available, but they are many times less), and on additional more interesting and difficult training material. 
- Creative tasks add variety to the learning process, brighten up some routine work, and make you look for non-standard options for completing tasks. Bright images also affect the process of memorizing and learning the educational material. For example, a simple retelling of the text will help the student analyze and systematize the information received. But if you play a small scene instead of a retelling, then a bright image will be added, and the information will be remembered better. Videos made during these classes will attract the attention of most students and future generations, which will create a positive atmosphere and motivation for the subject. Now it has become popular to shoot live-action short films where students work in creative groups, write scripts, dialogues, etc. Such films are used to attract applicants, advertise the University, and, of course, have a positive effect on the educational process itself.

- Offer elements of distance learning that allow you to receive tasks, consultations, and submit completed work without visiting a University. Full-time training is the most effective form of training. Replacing it with a remote one means a loss in quality. Therefore, only part of the course tasks can be completed remotely. However, such technology must be applied and improved. For example, if students for some reason cannot attend full-time classes for a certain time during the semester (due to illness, or family circumstances), then to avoid debts, or the loss of the school year, it is quite possible to use distance learning technologies. Another example of using distance learning elements is organizing work in large groups of students, where it is not possible to interview each student and check the performance of the work in the classroom.

Electronic learning tools are constantly being improved. They combine very well with traditional training. For example, students ' written papers can be uploaded to an electronic resource in the form of photos, which are now digital and made instantly. Cameras and video cameras are embedded in mobile phones, which in turn are connected to electronic platforms via the mobile Internet. Another example is oral responses, some of which can be presented as video recordings-reading and retelling text, monologues, dialogues, and more.

Students are very interested in remote technologies. The growing popularity of blogs that are posted on social networks also captures some elements of higher education. Normal entertainment can be used as the basis for completing tasks. For example, two students videotaped a small dialogue in a foreign language on the topic "the Realities of the United States of America" in a restaurant of an American fast food chain. They told us in detail and showed the features of American food, made a small excursion into the history of American development and, of course, had a good time.

Various forms of presentation of the acquired educational material. For students, the most psychologically disturbing moment in the classroom is the demonstration of knowledge. That is, a call to the Board, a test, or a regular survey often causes some excitement, and even some barrier, when a person can not even say a word. Here, the level of training and individual psychological qualities play an important role. It happens that even a well-trained student is simply shy to demonstrate their knowledge in the audience. Also, the possible presence of certain defects in speech or behavior that are undesirable to demonstrate in public. In a regular study group, these factors can be the cause of academic failure and debt.

Modern information and communication technologies make it possible to diversify and individualize the process of presenting the learned material. At the same time, students can work both in groups and in their own individual space. Moreover, the student and the teacher can be both nearby and at a distance.

Quality control of learning material. Verification of acquired knowledge and skills is one of the most important tasks in the learning process. Control helps to correct the course progress, shows gaps in learning and teaching, motivates learning of educational material, even if the final goals of the student have not been set yet (for example, the course of study 
takes place formally, only for evaluation in the diploma). Periodic quality control of learning material systematizes the acquired knowledge, sums up a certain result in the course sections and sets the student to move forward.

In the process of checking the quality of learning material we are guided by two principles:

- the student must know the answer;

- the student must come to the answer by reasoning.

English has a clear analytical structure, where there are very few exceptions to the rules, however, it is a language spoken by people of a very large part of the Earth, making multinational and territorial changes there. Therefore, it is easy to combine both principles in quality control.

Clear answers where there are no alternatives checked by passing various tests. The test material is developed on the basis of texts, grammatical and lexical exercises offered during training. The tests themselves are electronic, and are built on the basis of Internet platforms that are at the disposal of every modern University.

In addition to checking the quality of knowledge, tests have another function - training. For example, the same grammatical phenomena repeated in different combinations over the course of one or more tests are easy to remember, even without learning the rules. This way you can reduce the mass typical errors of students.

\section{Conclusion}

Electronic test tasks save time for both the student and the lecturer due to automated verification, the results of which can be used to create graphs and diagrams to illustrate the ratings of each student individually, study group, course flow, etc. Visualization of the test control results helps the student to see their strengths and weaknesses in the process of work.

Another principle, where the student needs to reason and analyze, is suitable for controlling oral statements, reading and translation, and written works. This kind of knowledge control can be combined with creative tasks, which for the student will not look like an exam or test. Although, on the other hand, the student may not take it very seriously. However, this can be easily corrected with additional instructions for the task.

Students have the following quality control of skills and abilities:

- ability to read;

- ability to write;

- ability to speak;

- ability to understand;

- ability to organize information.

Reading texts train articulation and visual memory. As a person can correctly pronounce words, so in the future he can speak and think logically. Accordingly, checking the quality of work on reading can show the approximate level of preparation of the student for further work. For example, if he makes mistakes in reading, it is unlikely that the retelling of the text will be a level higher. And, these two parameters can already be used to judge the quality of training and significantly save time in classroom lessons.

By regularly monitoring knowledge during the learning process, you can significantly ease the task at the end of the course on the final exam. The exam for most students is a significant stress. Accordingly, setting a final grade for intermediate course results is a very good reward for successful study during the semester and an additional incentive and motivation to study. Writing trains the mind and logic, affects a person's sense of touch and thus gives them the opportunity to remember information better. When monitoring a 
student's written work, we pay attention to the handwriting, which can be used to determine the affiliation of the work; to typical errors, while making a conclusion about the quality of the study material; to the logic of changing the material and its compliance with the rules of the language.

Speaking is one of the most important skills in both native and foreign languages. "He speaks fluently" is the most important criterion of language proficiency. In repetition, the literacy and personality of the utterance are checked, and, accordingly, the course of a person's thoughts. Speaking control can be performed both in monologue statements and in dialogues and discussions.

Another important language skill is the ability to understand both written and oral speech. Written comprehension is tested in translations, tests, and vocabulary exercises. Understanding spoken language is easy to test in conversation and discussion, and, of course, in audio and video tests and exercises.

The ability to organize information is the ability to put your thoughts in order. In principle, this criterion shows the fullness and quality of the study material. For example, a retelling of a text shows how the student understood it, learned unfamiliar words, how he can pronounce words, build sentences grammatically correctly, the logic of an utterance, and much more.

\section{References}

1. B.G. Ananyev, To the Psychophysiology of Student Age, Modern Psychological and Pedagogical Problems of Higher Education, 3, 3-15 (1974)

2. L.N. Stolovich, About universal values, Questions of philosophy, 7, 86-97 (2004)

3. L.D. Stolyarenko, Fundamentals of Psychology (Rostov-on-Don, Phoenix, 1997)

4. E.V. Yakovlev, Pedagogical Concept: Methodological Aspects of Construction (Moscow, VLADOS Humanitarian. Publ. Center, 2006)

5. V.A. Yasvin, Examination of the School Educational Environment, School Director, 11-15 (September, 2000)

6. I.A. Zimnyaya, Pedagogical psychology (Moscow, Logos 2000)

7. O.A. Chekun, Pedagogical Conditions for Preparing Students for Intercultural Communication: the Example of Non-Linguistic Faculties of the University, Retrieved from http://www.dissercat.com/content/pedagogicheskie-usloviya-podgotovkistudentov-k-mezhkulturnoi-kommunikatsii-na-primere-neyaz\#ixzz5gwSZuaEw (in Russ.) (accessed 01.03.2019)

8. F. Kröber, H. Klakhon, L.E. White, About Culture. Culture as a Word and as a Scientific Concept, Retrieved from https://students-library.com/library/read/41726kultura-kak-slovo-i-kak-naucnoe-ponatie-f-kreber-h-klakhon-i-le-uajt-o-kulture (accessed 03.03.2019)

9. N. Davitishvili, Cross-Cultural Awareness and Teaching English as a Second Language in the Context of Globalization, Sino-US English Teaching, 14 (9), 549-558. DOI:10.17265/1539-8072/2017.09.003 (2017)

10. Intercultural Communication Diary. European Context, Key Concepts and Theoretical Foundations, Retrieved from http://www.coe.int/t/dg4/autobiography/Source/AIE_ru/ AIE_context_concepts_and theories_ru.pdf (accessed 28.02.2019) 
11. V.N. Karpenko, Formation of Experience of Intercultural Interaction among Future Specialists in the Socio-Cultural Sphere, Retrieved from http://www.dissercat.com/content/formirovanie-opyta-mezhkulturnogovzaimodeistviya-u-budushchikh-spetsialistov-sotsiokulturno\#ixzz5h0pMk3MA. (accessed 03.03.2019)

12. G.M. Kodzhaspirova, Pedagogical Dictionary (Moscow, Academy Publishing Center, 2005)

13. O.K. Kozlitina, Pedagogical Support as a Condition for Students to Overcome Difficulties in Intercultural Iinteraction: on the Basis of Classes in a Foreign Language at University, Retrieved from http://www.dissercat.com/content/pedagogicheskaya-podderzhka-kak-usloviepreodoleniya-studentami-zatrudnenii-v-mezhkulturnom-\#ixzz5h0qLSa63 (accessed 28.02.2019)

14. Yu.A. Romanov, T.A. Snegurova, Intercultural communication and teaching Russian to international students at language summer courses, Integration of Education, 21(3), 371-384, Retrieved from https://cyberleninka.ru/article/n/ intercultural-communicationand-teaching-russian-to-international-students-at-language-summer-courses (accessed 05.08.2019), DOI: 10.15507/1991-9468.088.021.201703.371-384 (2017)

15. N.V. Polikasheva, Designing a System of Multicultural Education in Institutions of Additional Education of Children (Moscow, 2012) 